\title{
Modelagem computacional da dinâmica de evacuação em locais de reunião de público
}

\author{
Computational modeling of evacuation dynamics in places \\ of assembly
}

\section{Diego de Souza Martins \\ Andréa Carla Lima Rodrigues George Cajaty Barbosa Braga}

\section{Resumo}

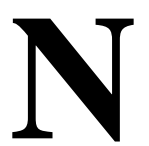

este trabalho são estudados os parâmetros relativos à evacuação em locais de reunião de público e às normas atinentes a saídas de emergência, buscando avaliar sua contemporaneidade diante do processo evolutivo das construções e das mudanças sociais. Para o desenvolvimento da pesquisa selecionou-se uma edificação classificada como clube social e dados obtidos por meio de projetos e vistoria in loco que pudessem subsidiar uma modelagem computacional. O software de evacuação utilizado foi o Pathfinder, que propicia dois modos de simulação, o SFPE e o Steering, tendo o primeiro uma metodologia semelhante à utilizada pelas normas vigentes, e o segundo um modelo que se aproxima do movimento esperado das pessoas em uma situação real. Com as simulações obtiveram-se dados de tempo de evacuação, fluxo específico, taxa de fluxo e dinâmica de evacuação, sendo possível identificar locais de congestionamento, gargalos e obstáculos. As conclusões mostraram que o nível de segurança propiciado pelas normas de saídas de emergência para a edificação estudada e destinada à reunião de público não é o esperado. Mesmo normas que passaram por recentes atualizações ainda são fruto de uma revisão meramente prescritiva, não propiciando condições ao desenvolvimento de soluções inovadoras, econômicas e principalmente mais seguras.

Palavras-chave: Evacuação de edifícios. Normas de saídas de emergência. Clubes sociais.

\section{Abstract \\ This article analyses the parameters related to evacuation in places of assembly and the technical standards associated with emergency exits, seeking to estimate their contemporaneity due to the evolution process of buildings and social changes. To undertake the study, the researchers selected a building classified as a social club, as well as data obtained from architectural plans and inspections at the site that could be used to create a computer model. The evacuation software used was Pathfinder, which provides two simulation models, SFPE and Steering, the former having a methodology similar to the one used by the current standards and the latter, a model that approaches that of the expected movement of people in a real situation. With the simulations, data on evacuation time, specific flow, flow rate, and evacuation dynamics were obtained, with the possibility of identifying congestion points, bottlenecks and obstacles. The conclusions showed that the safety level provided by the emergency exit standards for the building studied and destined for public assembly is not as expected. Even recently updated technical standards are still fruit of a merely prescriptive review, and do not provide conditions for the development of innovative, economic and, above all, safer solutions.}

Recebido em 03/07/18

Aceito em 04/09/18 


\section{Introdução}

As últimas décadas foram marcadas por tragédias, nacionais e internacionais, associadas a locais de reunião de público. Exemplo disso foi a morte de 21 pessoas, em 2003, na danceteria E2 (ChicagoEUA), a maior parte ocasionada por esmagamento, devido à pressão exercida pela multidão de pessoas que fugia da edificação após uma briga. Em 2013, um incêndio na boate Kiss (Santa Maria, Brasil) foi responsável pela morte de 242 pessoas. Em Paris, França, 112 pessoas morreram na boate Bataclan após atentado terrorista em 2015. Essas tragédias têm em comum o fato de ocorrerem em edificações classificadas como clubes sociais e que o adequado dimensionamento de saídas de emergência poderia ter colaborado sensivelmente para redução da quantidade de mortes ou para a não ocorrência delas.

Os locais de aglomeração, independentemente de suas características construtivas ou finalidades, apresentam riscos elevados devido à grande quantidade de pessoas reunidas. A principal medida de segurança para diminuir o risco de desastres é a existência de saídas de emergência que possibilitem uma evacuação rápida e segura.

Historicamente, a maioria dos eventos que demandam uma rápida evacuação está relacionada a incêndios, sendo esse o motivo para as saídas de emergência serem incluídas como medidas de segurança nas normas contra incêndio. No Brasil, cada estado tem seu regramento próprio atinente ao dimensionamento das rotas de fuga e, quando não o possui, geralmente seguem a norma brasileira.

Com características de serem baseados nas experiências do passado, tais regramentos ficaram conhecidos como códigos prescritivos e dizem como alcançar a segurança contra incêndio sem deixar claro quais são as intenções das recomendações sugeridas, por vezes aumentando o custo dos projetos sem garantir o nível de segurança almejado (TAVARES, 2008). Para Alves, Campos e Braga (2008), como a legislação prescritiva determina a adoção dos requisitos de segurança contra incêndio de forma empírica, dificulta a implantação de soluções tecnologicamente inovadoras.

É necessário, no entanto, avançar em pesquisas que possibilitem o uso de parâmetros baseados em desempenho. Segundo Tavares (2008), os parâmetros baseados em desempenho são códigos dinâmicos, pois levam em consideração agentes envolvidos no sistema como a evolução do incêndio, as características da edificação e o comportamento das pessoas. Os parâmetros de desempenho, a exemplo dos estudos utilizando modelos matemáticos, também permitem a redução do risco de tragédias a partir da detecção de situações potencialmente perigosas, diminuindo a possibilidade de ocorrência e aumentando a segurança das edificações e o equilíbrio da relação custo-benefício.

Diante do exposto, a presente pesquisa tem como objetivo principal discutir a eficiência normativa quanto ao dimensionamento das saídas de emergência em edificações de reunião de público a partir da modelagem de evacuação usando parâmetros de desempenho.

\section{Fundamentação teórica}

\section{Saídas de emergência em locais de reunião de público}

Segundo Ono (2007), é possível agrupar as medidas de segurança contra incêndio em medidas de prevenção destinadas a prevenir a ocorrência do incêndio e medidas de proteção que resguardam a vida humana e os bens materiais dos efeitos nocivos do incêndio que já se desenvolve. Entre as medidas de proteção mais importantes estão as saídas de emergência.

A norma brasileira NBR 9077 (ABNT, 2001) Saídas de emergência em edifícios - é o regulamento que aborda o tema no país, e que, por sua vez, subsidiou a Instrução Técnica do Corpo de Bombeiros da Polícia Militar de São Paulo IT 11 (CORPO..., 2018a) - Saídas de emergência sendo, portanto, documentos muito similares. Diferenciam-se devido ao fato de a norma estadual ter passado por várias atualizações (2004, 2011, 2014 e 2018), enquanto a última versão da norma brasileira foi publicada em 2001, há quase duas décadas. Tamanho tempo sem revisão contraria a instrução administrativa da Associação Brasileira de Normas Técnicas (ABNT, 2014), conforme a qual uma norma brasileira deve ser revista a cada cinco anos.

Claret e Mattedi (2011) afirmam que a NBR 9077 (ABNT, 2001) é considerada a “norma-mãe”, entre os engenheiros e arquitetos, pois direciona qualquer atividade projetual no que concerne às edificações. Já a IT 11 (CORPO..., 2018a) é a regulamentação de saídas mais avançada do país. Ainda segundo o autor, tais normas interferem de forma significativa na tomada de decisão e na liberdade projetual, conduzindo a soluções padronizadas e pouco flexíveis.

Os parâmetros normativos utilizados no dimensionamento das saídas de emergência estão 
diretamente associados à ocupação da edificação, à densidade ocupacional e aos conceitos de unidade e capacidade de passagem. A ocupação corresponde ao uso da edificação e está vinculada à função social, econômica, comercial ou técnica exercida em uma edificação. Ela é utilizada pelas legislações nacionais e estaduais de segurança contra incêndio para classificar as edificações em grupos, a exemplo da NBR 9077 (ABNT, 2001) e da IT 11 (CORPO..., 2018a), que apresentam os locais de reunião de público pertencentes ao grupo F. Para o presente estudo, a subdivisão F-6, definida como clubes sociais, salões de baile, restaurantes dançantes e assemelhados, é mais relevante.

As saídas de emergência são dimensionadas em função da população da edificação e são calculadas através dos coeficientes de densidade ocupacional. A NBR 9077 (ABNT, 2001) e a IT 11 (CORPO..., 2018a) apresentam duas definições necessárias para o entendimento das equações de dimensionamento de saídas:

(a) unidade de passagem (UP), fixada em 0,55 m, que é a largura mínima para a passagem de uma fila de pessoas; e

(b) capacidade de uma unidade de passagem (C), que é o número de pessoas que passa por esta unidade durante o intervalo de $1 \mathrm{~min}$.

Assim, o número de unidades de passagem $(\mathrm{N})$ é dado pela Equação 1 e a largura das saídas de emergência (m) é calculada pela Equação 2.

$N=\frac{P}{C}$

Onde:

P é a população (pessoas) calculada através da densidade ocupacional dada pela relação número de pessoas $/ \mathrm{m}^{2}$; e

C é a capacidade da unidade de passagem (pessoas).

$L=N \times U P$

Onde:

$\mathrm{UP}=0,55 \mathrm{~m}$ correspondente a uma unidade de passagem; e

$\mathrm{N}$ é o número de unidades de passagens calculado pela Equação 1 e adimensional.
No Quadro 1 são mostrados os valores do coeficiente de densidade ocupacional e da capacidade da unidade de passagem para clubes sociais, segundo a NBR 9077 (ABNT, 2001) e a IT 11 (CORPO..., 2018a).

Outro conceito importante no estudo das saídas de emergência é fluxo específico. Conforme Valentin (2008) o fluxo específico representa o número de pessoas que passa em um ponto da rota de escape por unidade de largura efetiva e de tempo, e é dado pela Equação 3.

$F_{e}=D x v$

Eq. 3

Onde:

$\mathrm{F}_{\mathrm{e}}$ é o fluxo especifico (pessoas/m.s);

$\mathrm{D}$ é a densidade (pessoas $/ \mathrm{m}^{2}$ ); e

$\mathrm{v}$ é a velocidade $(\mathrm{m} / \mathrm{s})$.

Considerando que para locais de reunião de público a capacidade de uma unidade de passagem $(0,55 \mathrm{~m})$ para portas e acessos é 100 pessoas por minuto, temse um fluxo específico de 3,03 pessoas/(segundo.metro), à luz da NBR 9077 (ABNT, 2001) e da IT 11 (CORPO..., 2018a).

Já a taxa de fluxo (Equação 4) representa o número de pessoas que cruzam um determinado ponto em uma unidade de tempo.

$T=F_{e} x L$

Eq. 4

Inde:

T é a taxa de fluxo (pessoas/s);

$\mathrm{F}_{\mathrm{e}}$ é o fluxo especifico (pessoas/m.s); e

L é a largura (m).

Com relação ao tempo de evacuação (Figura 1), Gouveia e Etrusco (2002) explicam que em uma edificação esse tempo é composto de várias parcelas:

(a) tempo de detecção: tempo decorrido entre o início e à detecção do sinistro;

(b) tempo de alarme: tempo desde a detecção até à notificação dos ocupantes;

(c) tempo pré-evacuação: tempo decorrido entre a notificação dos ocupantes e o início da evacuação; e

(d) tempo de movimento: tempo decorrido entre o início do abandono e a completa evacuação.

Quadro 1 - Parâmetros para cálculo de população e largura de saídas de emergência em clubes sociais

\begin{tabular}{|c|c|c|c|}
\hline \multirow{2}{*}{ Divisão } & População & \multicolumn{2}{c|}{ Capacidade da unidade de passagem (C) } \\
\cline { 2 - 4 } & Densidade ocupacional & Acessos e descargas & Portas \\
\hline F-6 & Duas pessoas por metro quadrado de área $\left(1: 0,5 \mathrm{~m}^{2}\right)$ & 100 & 100 \\
\hline
\end{tabular}

Fonte: adaptado da NBR 9077 (ABNT, 2001) e IT 11 (CORPO..., 2018a). 
Figura 1 - Tempos para evacuação da edificação

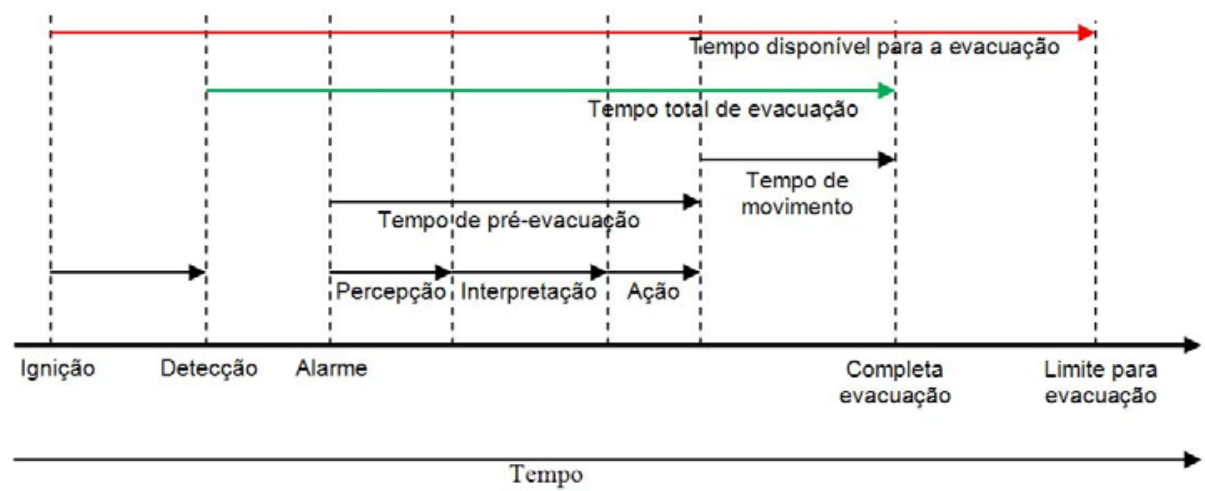

Fonte: adaptado de DiNenno et al. (2002).

O intervalo de tempo em que o edifício conserva as condições necessárias para sua evacuação total se processar em segurança é chamado de tempo disponível e deve ser superior ou, no mínimo, igual ao tempo total de evacuação. A NBR 9077 (ABNT, 2001) e a IT 11 (CORPO..., 2018a) não estabelecem o tempo de evacuação das edificações, mas permitem o entendimento de que ocorrerá em 1 min, pois usa esse tempo como referência para os valores dados de capacidade de passagem.

A determinação do tempo necessário para a evacuação de uma edificação consiste num desafio notório, pois o número de variáveis a considerar é enorme. Nesse sentido, os modelos matemáticos têm colaborado muito, servindo como ferramentas de apoio à tomada de decisão.

\section{Modelos computacionais de evacuação}

Os modelos computacionais de evacuação são ferramentas de uso crescente da engenharia de segurança contra incêndio (ONO, 2010). Segundo Valentin (2008), os modelos de evacuação podem ser categorizados em modelo de movimento, de comportamento parcial e comportamental. Os modelos de movimento simulam o deslocamento do ocupante de um ponto no interior da edificação para uma saída ou área segura. No modelo parcial já é possível simular comportamentos pouco complexos como o de ultrapassagem. Os modelos comportamentais podem incorporar a tomada de decisão ou ações desempenhadas devido às condições ambientais.

Os modelos computacionais têm sido utilizados, em nível mundial, para estimar o tempo de evacuação e simular o crescimento de um incêndio em edificações. Assim, tais modelos servem tanto para avaliar projetos existentes ou analisar catástrofes que levaram a múltiplas mortes, como para estudar novos projetos de elevada complexidade (ONO, 2007).

No Brasil, ainda se observam poucas pesquisas envolvendo modelos de evacuação apesar da importância do tema e da necessidade do desenvolvimento de estudos baseados em parâmetros de desempenho. Nesse sentido, Montenegro (2016), Ono e Vitorino (2010), Sena e Ono (2010), Valentin (2008), Alves, Campos e Braga (2008) e Souza (2007), utilizando modelos diversificados, a exemplo de Building Exodus, Fire Dynamics Simulator (FDS), Simulex, Evac e Pathfinder, concluíram que a utilização de programas computacionais para a simulação de escape é de grande importância para identificar soluções aceitáveis de segurança contra incêndio em situações diversas.

Cada modelo possui características e aplicabilidades específicas, necessitando que o usuário tenha conhecimento aprofundado dos conceitos da evacuação de edificações para não chegar a conclusões erradas. Na presente pesquisa utilizou-se o modelo Pathfinder para realização das simulações de evacuação em clubes sociais por possibilitar variações no movimento dos ocupantes, visualização tridimensional, entre outras características.

\section{Modelo Pathfinder}

Pathfinder é um modelo de evacuação baseado em agentes que utilizam duas maneiras para modelar o movimento dos ocupantes: SFPE e Steering. Os resultados são apresentados de forma qualitativa e quantitativa através da disponibilização de dados de tempo de evacuação, taxas de fluxo e da representação visual da densidade populacional no tempo durante o processo de evacuação (RONCHI et al., 2010).

Conforme Muniz (2013), o ambiente de circulação é uma malha 3D triangulada concebida para 
corresponder às dimensões reais da construção modelada. Essa malha de circulação pode ser introduzida automaticamente com base em dados importados. Os ocupantes são modelados como cilindros na posição vertical e seus movimentos são calculados de forma independente, a partir de um conjunto de parâmetros de entrada.

\section{Modo SFPE}

Este modelo aplica as técnicas de modelagem baseadas em fluxo de escape apresentadas no Manual de Engenharia de Proteção Contra Incêndio da Society of Fire Protection Engineers (SFPE) dos EUA (NELSON; MOWRER, 2002) e no Guia de Engenharia da SFPE - Comportamento Humano em Incêndios (SOCIETY..., 2017). No modo SFPE, os ocupantes se movem entre os ambientes através de filas e não tentam evitar um ao outro. As portas funcionam como o principal controle de fluxo e a velocidade é influenciada pela densidade de cada setor, através da Equação 5. Para densidades iguais ou superiores a 3,8 pessoas $/ \mathrm{m}^{2}$ a Equação 5 tenderá a zero, indicando que o movimento irá parar.

$v=1,40-(0,372 * D)$

Eq. 5

Onde:

$\mathrm{v}=$ velocidade $(\mathrm{m} / \mathrm{s}) ; \mathrm{e}$

$\mathrm{D}=$ densidade (pessoas $/ \mathrm{m}^{2}$ )

O fluxo Específico (Equação 3) é calculado e multiplicado pela largura efetiva de cada porta para obter a taxa de saída dos ocupantes por unidade de tempo. No SPFE são considerados os ocupantes que estão na fila para passar pela porta no momento atual. Isso inclui apenas os ocupantes que realmente chegaram à porta e estão esperando para sair. Aqueles que estão empilhados à espera de chegar a uma porta não são computados. Esse modo usa o conjunto simples de suposições e não é muito suscetível aos padrões geométricos e irregularidades de movimento que podem fazer com que os ocupantes fiquem presos (SOCIETY..., 2017).

Os valores sugeridos pela NBR 9077 (ABNT, 2001) para o dimensionamento das saídas de emergência são bem retratados por esse modelo, uma vez que a referida norma utiliza metodologias de cálculo fundamentadas na unidade de passagem, que é baseada no movimento de pessoas em fila.

\section{Modo Steering}

É um modelo baseado na metodologia de comportamentos de direção desenvolvida por Reynold (1999) e refinada por Amor, Murray e Obst (2006), permitindo uma análise mais complexa alinhada com uma representação dos processos humanos, no qual surgem os congestionamentos. Circunstâncias mais complexas podem emergir naturalmente como subprodutos dos algoritmos de circulação eliminando a necessidade explícita de filas em portas, embora ainda possam ocorrer, e cálculos de densidade.

Buscando aproximar-se da realidade, o modelo Steering desloca os ocupantes para que eles realizem seus objetivos e possam responder a um ambiente em mudança, através da avaliação de um conjunto de instruções de movimento. Esse modo é mais dependente da prevenção de colisões (seres humanos ou paredes) e da interação entre ocupantes produzindo respostas mais similares aos dados experimentais do que o modo SFPE (ALMEIDA, 2012).

\section{Método de pesquisa}

A presente pesquisa é do tipo quantitativa, de natureza prática e objetivo explicativo. É assim classificada, pois utiliza a modelagem matemática para simular, por meio de um estudo de caso, a dinâmica das pessoas em situação de evacuação em locais de reunião de público sob diferentes condições de movimento, largura e posicionamento de saídas. Tem objetivo explicativo, pois permite gerar conhecimentos que podem subsidiar a modificação de normas técnicas sobre aspectos relacionados ao dimensionamento de saídas de emergência e, assim, possibilitar a realização de projetos que promovam maior segurança aos usuários em locais dessa natureza.

Conforme ilustrado na Figura 2, a pesquisa foi desenvolvida em quatro fases:

(a) aquisição de dados;

(b) desenvolvimento da modelagem matemática;

(c) avaliação das simulações; e

(d) discussão quanto à eficiência das normas de saídas em locais de reunião de público.

A fundamentação teórica esteve presente em todas as fases.

\section{Fase 1: aquisição de dados}

A primeira fase da pesquisa foi a aquisição de dados para alimentação do modelo matemático. Como o estudo se aplica às edificações classificadas como clubes sociais, foi escolhida uma edificação com características típicas e representativas de tal categoria. Outros critérios para essa escolha foram a autorização do proprietário, a existência de projeto arquitetônico e de Projeto de Segurança Contra Incêndio (PSCI) obtidos com o quartel do Corpo de Bombeiros Militar da Paraíba (CBMPB). 
Com o intuito de delimitar o estudo ao movimento horizontal, optou-se por uma edificação de apenas um pavimento e com população superior a 100 pessoas, uma vez que, acima desse número, são aumentadas as exigências de segurança nesses locais.

A partir dos projetos arquitetônicos e de incêndio verificou-se que a edificação utilizada no estudo possui pé-direito de $3 \mathrm{~m}$ e área construída de 739 $\mathrm{m}^{2}$. Apresenta duas saídas de emergências distanciadas $10 \mathrm{~m}$. A saída 1, que também é a entrada principal, é acessada por uma escada contendo três degraus e 1,20 m de largura, e o acesso à saída 2 é feito por uma rampa de 4,0 m de largura, conforme ilustrado na Figura 3.

A área total é subdividia em ambiente para clientes, com $400 \mathrm{~m}^{2}$, área privativa para funcionários com $136 \mathrm{~m}^{2}$ e demais áreas da edificação que totalizam $203 \mathrm{~m}^{2}$. A população máxima permitida a partir do parâmetro da área construída e utilizando apenas as áreas reservadas ao público e aos funcionários é de 819 pessoas.

\section{Fase 2: desenvolvimento da modelagem matemática}

Conforme Thunderhead Engineering (2018), a validação do software Pathfinder foi feita com base na Nota Técnica 1822 da NIST (The Process of Verification and Validation of Building Fire Evacuation Models), que apresenta os testes de validação descritos em relação aos cinco principais elementos disponíveis em modelos de evacuação:
(a) tempo de pré- evacuação;
(b) movimento e navegação;
(c) uso da saída;
(d) disponibilidade de rotas; e
(e) condições de fluxo/restrições.

A validação do modelo também foi verificada em outros estudos, a exemplo de $\mathrm{Ni}$, Li e Li (2017), Lantz (2015), Szilagyi (2013) e Kuligowski, Peacock e Hoskins (2010).

Figura 2 - Descrição das fases de desenvolvimento da pesquisa

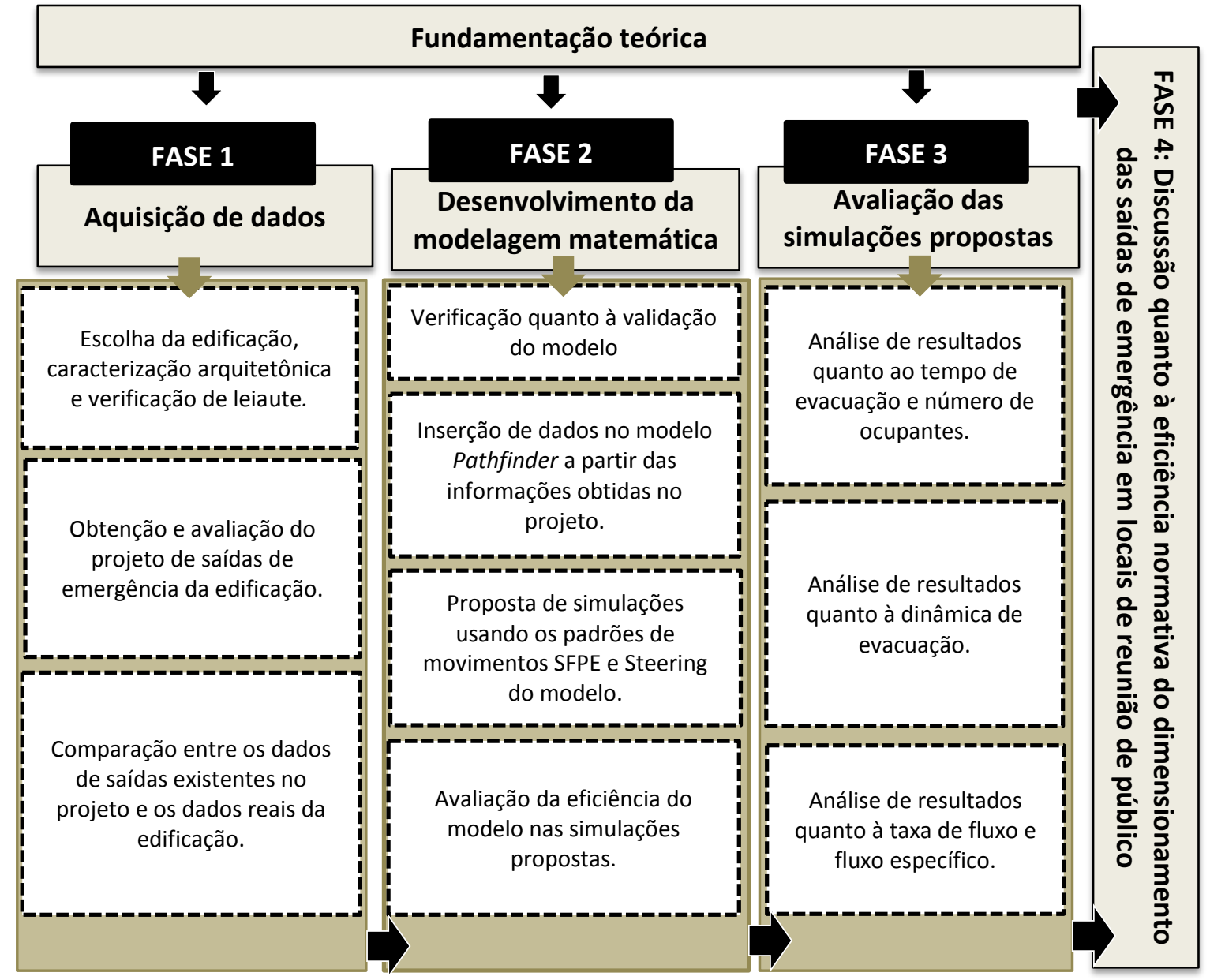


Figura 3 - Localização em planta das saídas da edificação e indicação da rota de fuga

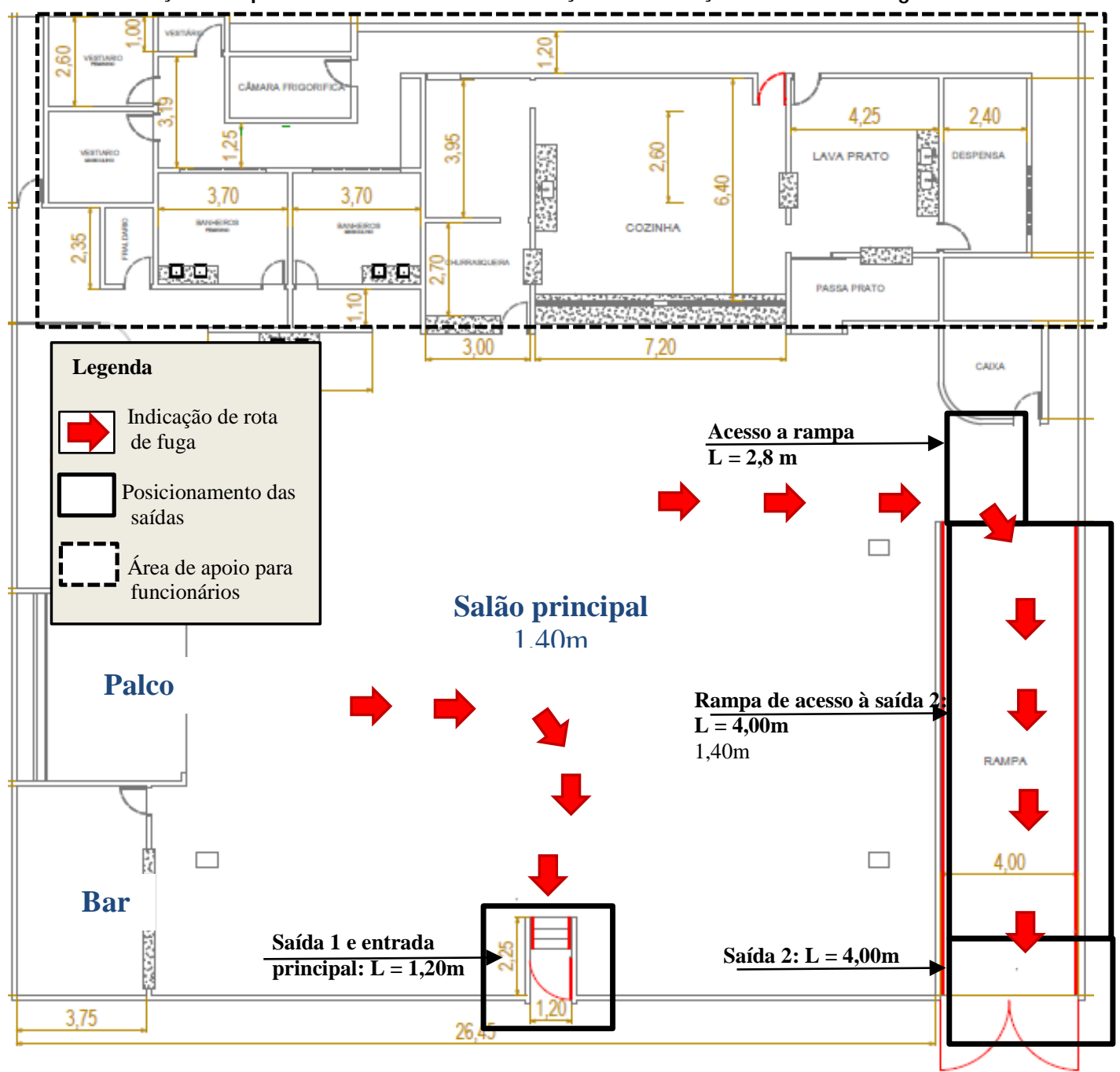

Fonte: arquivo do Corpo de Bombeiros Militar da Paraíba (2016).

Para as simulações foram utilizados parâmetros gerais e avançados (Quadro 2). Os parâmetros gerais são aplicáveis aos dois modelos de movimento (SFPE e Steering) e os avançados apenas ao Steering. Os ocupantes são dispostos randomicamente e são definidos considerando perfis e comportamentos. O perfil define características como velocidade máxima, diâmetro e avatar. O comportamento define uma sequência de ações que o ocupante tomará ao longo da simulação. Portanto, antes de gerar um resultado, as simulações são executadas várias vezes pelo software, garantindo, assim, respostas confiáveis.

Os demais dados (Quadro 3) foram incluídos no modelo de acordo com as informações extraídas dos projetos da edificação. De posse dos dados de entrada e utilizando os parâmetros gerais e avançados foram propostas duas simulações: a primeira utilizando o modo SFPE e a segunda utilizando o modo Steering, ambas com o intuito de obter respostas quanto à influência do movimento humano, da geometria e do dimensionamento de saídas de emergência, no tempo e na dinâmica de evacuação em clubes sociais.

O tempo aferido nas simulações foi o de movimento. Não foram inseridos tempos de detecção ou de pré-evacuação. Logo, todos os ocupantes iniciaram seu deslocamento no início da simulação. As simulações realizadas também serviram para avaliar a eficiência do modelo escolhido para o estudo.

\section{Fase 3: avaliação das simulações propostas}

Os resultados obtidos com as simulações foram avaliados sob dois aspectos: tempo de evacuação e dinâmica de movimento. O modo SFPE fornece a informação de quantas pessoas esperam em fila para sair de uma edificação. Essa medida é útil para analisar o congestionamento formado e, para tanto, 
na simulação 1, foram confeccionados gráficos representativos da situação citada. Para o modo Steering (simulação 2) tal dado não é informado pelo software, pois os congestionamentos podem ser identificados visualmente através de uma representação 3D. Em ambas as simulações foram analisadas também a relação número de ocupantes $\mathrm{x}$ tempo, as taxas de fluxo e o fluxo específico.

\section{Fase 4: discussão quanto à eficiência normativa do dimensionamento das saídas de emergência em locais de reunião de público}

Após concluída a fase 3 foi possível fazer uma discussão acerca dos níveis de segurança estabelecidos pelas principais normas de saídas de emergência utilizadas no Brasil para nortear os projetos de edificações de locais de reunião de público e que, atualmente, se baseiam em dados meramente prescritivos.

\section{Resultados e discussão}

\section{Simulação 1: modo SFPE}

A Tabela 1 apresenta os resultados obtidos para o tempo de evacuação após a simulação 1. Foram necessários 149,3 s, aproximadamente $2 \mathrm{~min}$ e meio, para a saída de todos os ocupantes da edificação. No entanto, observa-se que, decorrido 1 min, apenas $35 \%$ das pessoas conseguiram abandonar o local, não atendendo ao indicado pela NBR 9077 (ABNT, 2001) e pela IT 11 (CORPO..., 2018a), que estabelecem uma evacuação total no tempo de até $1 \mathrm{~min}$.

\section{Quadro 2 - Principais parâmetros gerais e avançados utilizados no modelo}

\begin{tabular}{|l|l|}
\hline \multicolumn{1}{|c|}{ Parâmetros gerais } & \multicolumn{1}{c|}{ Valores atribuídos } \\
\hline $\begin{array}{l}\text { Largura do ombro (igual ao diâmetro do cilindro que } \\
\text { representa o ocupante, usado para testes de colisão e } \\
\text { planejamento de trajetória durante as simulações). }\end{array}$ & $\begin{array}{l}\text { Padrão = 45,58 cm, que se aproxima da média } \\
\text { brasileira, a qual, segundo Bastos, Sabrá e } \\
\text { Rosa (2013), é 48,8 cm para homens e 44,7 cm } \\
\text { para mulheres. }\end{array}$ \\
\hline Velocidade máxima. & Igual a 1,19 m/s e calculada pela Eq. 5. \\
\hline \multicolumn{1}{|c|}{ Parâmetros avançados } & \multicolumn{1}{c|}{ Valores atribuídos } \\
\hline $\begin{array}{l}\text { Fator de redução (especifica quão bem um ocupante pode } \\
\text { se deslocar passando por outros em corredores apertados). }\end{array}$ & $\begin{array}{l}\text { Padrão = 0,7 (varia entre 0 e 1 e o valor 0,7 } \\
\text { permite que o ocupante comprima-se para 70\% } \\
\text { da largura do ombro). }\end{array}$ \\
\hline $\begin{array}{l}\text { Distância de conforto (especifica a distância desejada que } \\
\text { um ocupante tentará manter dos outros, como quando } \\
\text { esperando em filas). }\end{array}$ & Padrão = 0,08 m. \\
\hline $\begin{array}{l}\text { Tempo de persistência (tempo que o ocupante manterá } \\
\text { uma prioridade elevada ao tentar resolver conflitos de } \\
\text { movimento). }\end{array}$ & Padrão = 1,0 s. \\
\hline $\begin{array}{l}\text { Tempo de resposta a colisão (multiplicado pela } \\
\text { velocidade atual de um ocupante, controla a distância em } \\
\text { que a pessoa começará a calcular um custo para colidir } \\
\text { com outros ocupantes). }\end{array}$ & Padrão = 1,5 s. \\
\hline $\begin{array}{l}\text { Fator de demora (especifica uma fração da velocidade dos } \\
\text { ocupantes no qual eles são considerados lentos). }\end{array}$ & Padrão = 0,1. \\
\hline
\end{tabular}

Fonte: adaptado de Thunderhead Engineering (2018).

Quadro 3 - Dados de entrada para a edificação

\begin{tabular}{|c|c|c|}
\hline \multirow{2}{*}{ Geometria do PSCI } & \multirow{2}{*}{ Porta de saída 1} & Largura: 1,20 m \\
\cline { 2 - 3 } & \multirow{2}{*}{ Porta de saída 2} & 2 unidades de passagem \\
\cline { 2 - 3 } & & Largura: 4,00 m \\
\hline População & 819 ocupantes (91 por unidades de passagem \\
\hline
\end{tabular}

Tabela 1 - Tempo de evacuação na simulação1

\begin{tabular}{c|c|c|c|c}
\hline Tempo (s) & $\mathbf{6 0}$ & $\mathbf{9 0}$ & $\mathbf{1 2 0}$ & $\mathbf{1 4 9}$ \\
\hline Pessoas evacuadas & 289 & 470 & 650 & 819 \\
Percentual (\%) & 35 & 57 & 79 & 100 \\
\hline
\end{tabular}


A evacuação do primeiro ocupante ocorre através da descarga 1 no instante de $0,4 \mathrm{~s}$, enquanto a saída 2 é utilizada apenas a partir do instante 12,6 s. A diferença de tempo gasto pelos primeiros ocupantes para saírem do local é consequência do posicionamento das saídas 1 e 2, ou seja, do leiaute da edificação. A saída 1, que também é a entrada principal do recinto, está localizada no salão destinado aos clientes, já entre a descarga 2 e o setor do público existe um corredor de aproximadamente $14 \mathrm{~m}$, justificando o maior tempo.

Apesar da saída 2 está arquitetonicamente mais distante que a 1, observa-se, pela Figura 4, que 78\% das pessoas abandonam o local pela saída 2, enquanto apenas 22\% utilizam a saída 1 . Esse percentual é compreensível, uma vez que a saída 2 é bem mais larga que a 1 , o que permite maior taxa de fluxo.

A Figura 5 apresenta a dinâmica de evacuação no modo SFPE nos tempos 0 s, 15 s, 30 s e 120 s. Na Figura 5(a) é possível visualizar a distribuição randômica dos ocupantes na edificação antes do início da evacuação. As zonas vermelhas identificam regiões com maior concentração de pessoas, sendo a densidade máxima de 3 pessoas $/ \mathrm{m}^{2}$. Após iniciada a evacuação observamse as pessoas em filas na direção das saídas de emergência mantendo um movimento padronizado (Figura 5(b)).

Conforme Salyers e Jones (2011), as filas não são percebidas visualmente e os ocupantes parecem caminhar uns sobre os outros, pois o modo SFPE, por padrão, permite que várias pessoas possam ocupar o mesmo local. Decorridos 30 s de evacuação, 109 pessoas abandonaram o local
(Figura 5(c)). Apesar de não ser identificado visualmente, o número de ocupantes esperando nas filas formadas nas portas (pessoas aglomeradas) é fornecido pelo software. A Figura 5(d) é semelhante à Figura 5(c), embora representem quantidades diferentes de pessoas evacuadas em tempos distintos.

$\mathrm{Na}$ Figura 6 são apresentadas as curvas representativas do número de pessoas aglomeradas nas saídas 1 e 2 . Na saída 1 , o máximo valor acontece no tempo de $17 \mathrm{~s}$ quando 136 pessoas estão esperando para passar pela porta. Após esse instante, observa-se uma redução no acúmulo de pessoas, embora o valor ainda seja relativamente alto. Já na saída 2 , verifica-se um baixo número de pessoas aglomeradas. Isso acontece devido ao estreitamento do corretor de acesso à saída 2, que proporciona um ordenamento das pessoas durante a evacuação.

Em contrapartida, no acesso ao corredor da descarga 2 observa-se uma elevada aglomeração de pessoas, chegando, no instante $32 \mathrm{~s}$, ao número de 436 pessoas. Logo, uma análise meramente prescritiva poderia incorrer na conclusão que as maiores aglomerações se formariam no entorno das descargas 1 e 2, mas, como foi observado, o maior congestionamento deu-se no acesso ao corredor da descarga 2.

Conforme Zhang e Seyfried (2013), os valores de fluxo podem variar de acordo com as especificações e dados das diferentes literaturas, bem como os estudos experimentais diferem consideravelmente. Os dados referentes à taxa de fluxo e ao fluxo específico obtidos na simulação 1 estão apresentados na Tabela 2.

\section{Figura 4 - Gráfico do número de pessoas evacuadas por saídas $\mathbf{x}$ tempo na simulação 1}

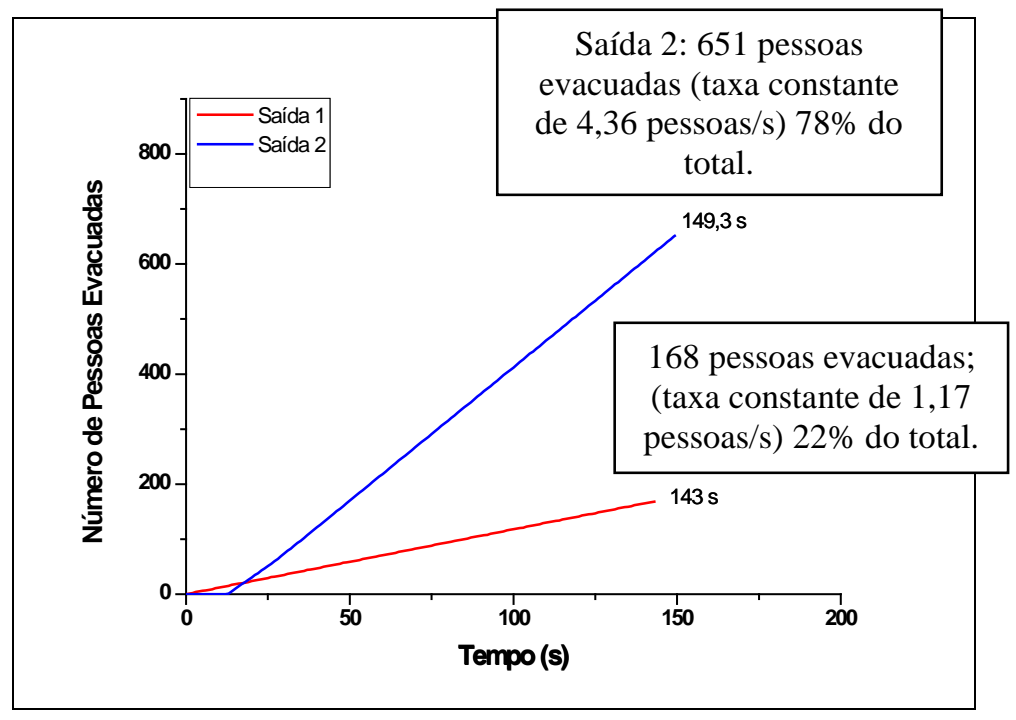


Figura 5 - Simulação 1 - Número de pessoas (p) evacuadas e tempo de desocupação (s): (a) 819 p e 0 s, (b) 26 p e 15 s, (c) 109 p e 30 s, (d) 649 p e 120 s

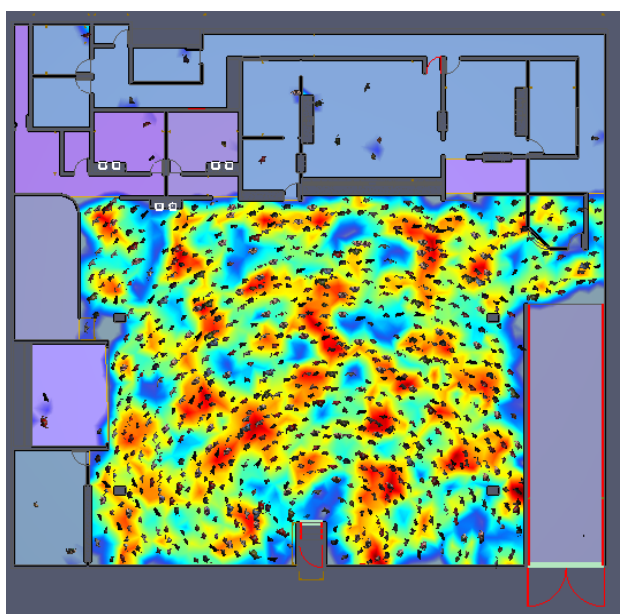

(a)

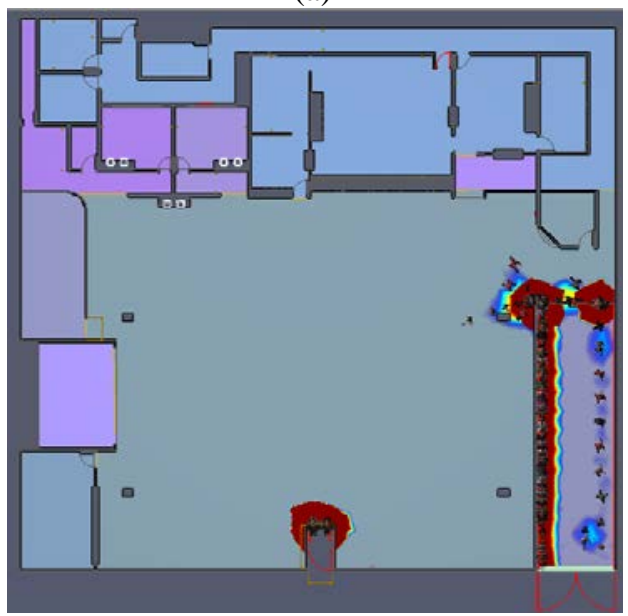

(c)

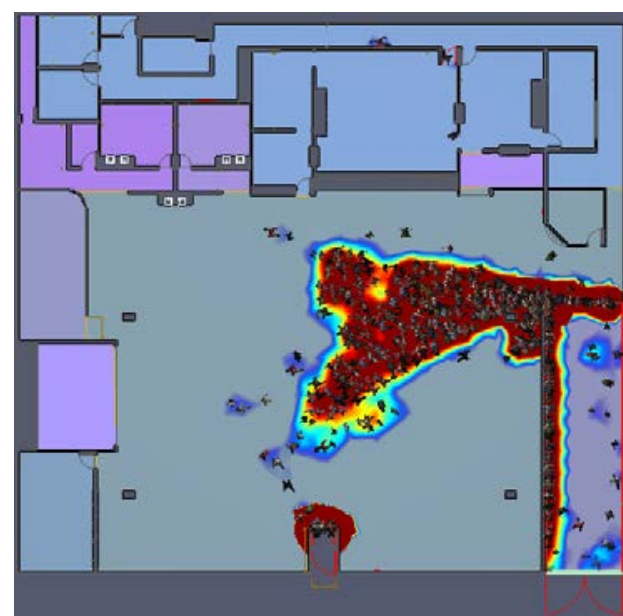

(b)

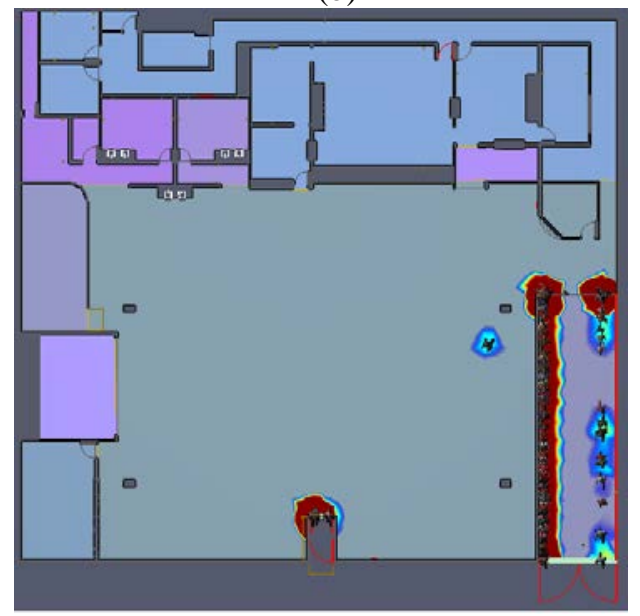

(d)

Densidade pessoas $/ \mathrm{m}^{2}$

$0,6 \quad 0,8 \quad 1,0 \quad 1,3 \quad 1,5$

$1,5 \quad 1,8$

2,5

2,7

Figura 6 - Gráfico do número de ocupantes esperando em fila na simulação 1

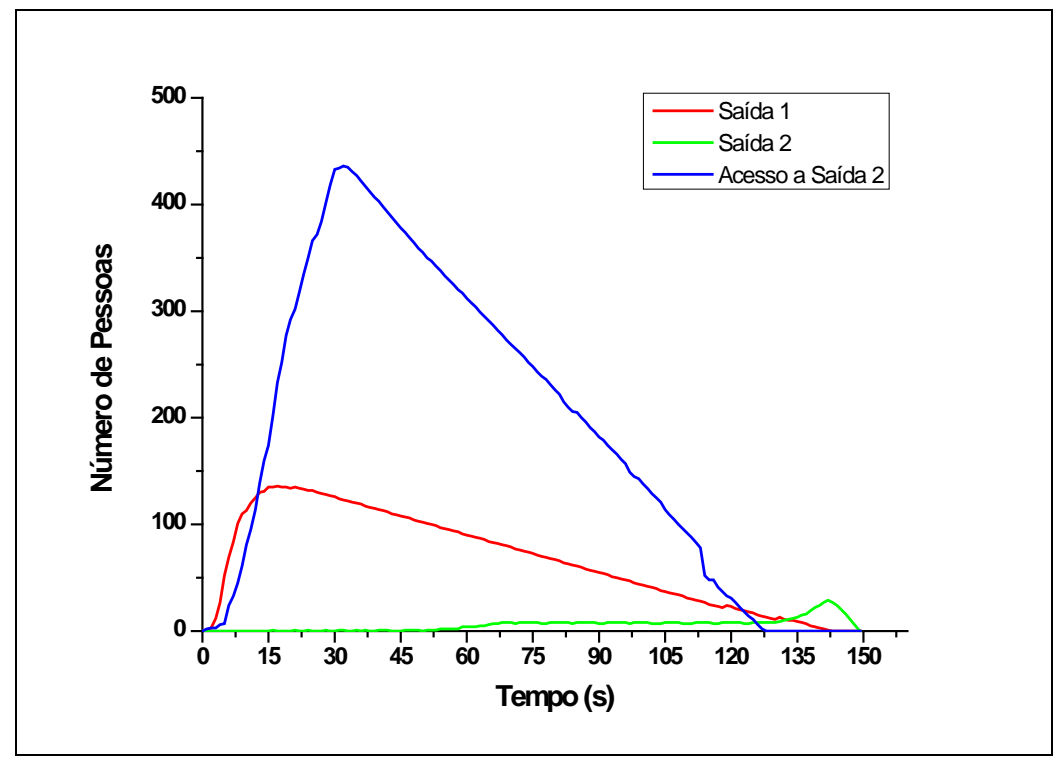


Tabela 2 - Fluxos específicos na simulação 1

\begin{tabular}{c|c|c|c|c}
\hline & \multicolumn{2}{|c|}{ Taxa de fluxo (pessoas/s) } & \multicolumn{2}{c}{ Fluxo específico (pessoas/s.m) } \\
\hline Saída & Média & Máxima & Médio & Máx \\
\hline $\mathbf{1}$ & 1,19 & 1,21 & 0,99 & 1,34 \\
$\mathbf{2}$ & 4,77 & 4,89 & 1,19 & 1,32 \\
\hline
\end{tabular}

Tabela 3 - Tempo de evacuação da simulação 2

\begin{tabular}{c|c|c|c|c|c}
\hline Tempo (s) & $\mathbf{6 0}$ & $\mathbf{9 0}$ & $\mathbf{1 2 0}$ & $\mathbf{1 5 0}$ & $\mathbf{1 8 5}$ \\
\hline Pessoas evacuadas & 271 & 396 & 578 & 720 & 819 \\
Percentual (\%) & 33 & 48 & 71 & 88 & 100 \\
\hline
\end{tabular}

Figura 7 - Gráfico do número de pessoas evacuadas por saídas x tempo na simulação 2

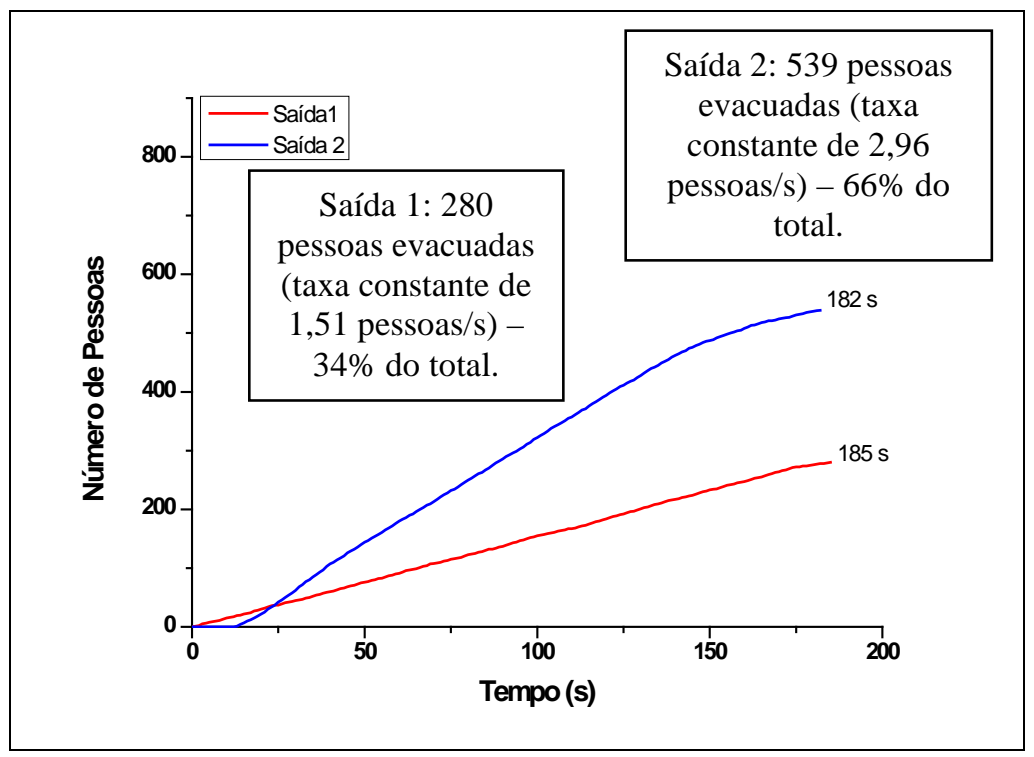

Pode-se observar que as taxas de fluxos média e máxima da saída 2 são cerca de quatro vezes os valores obtidos para a saída 1 , tendo em vista a maior largura da saída 2. Para a saída 1 o valor do fluxo específico médio foi 0,99 pessoas $/ m . s$, enquanto para a saída 2 foi 1,19 pessoas/m.s. Já os fluxos específicos máximos foram praticamente iguais, com valores de 1,34 e 1,32 pessoas/s.m, respectivamente, para as saídas 1 e 2 .

Segundo a NBR 9077 (ABNT, 2001) e a IT 11 (CORPO..., 2018a), em locais de reunião de público, de maneira geral em acessos, descargas e portas (passagens horizontais), a capacidade de uma unidade de passagem é 100 (ver Quadro 1), o que possibilita um fluxo específico de 3,03 pessoas/(s.m). Esse valor é bem superior ao encontrado na simulação, o que indica um subdimensionamento das saídas de emergência da edificação estudada se consideradas as especificações das normas nacional e de São Paulo.

\section{Simulação 2: geometria de PSCl e modo Steering}

Os resultados da simulação 2 mostraram um tempo total de evacuação de 185 s (Tabela 3), aproximadamente $3 \mathrm{~min}$. Esse tempo foi superior em 35 s ao de evacuação em fila proposta pelo modo SFPE (simulação 1). O dado indica que, em uma situação real, as pessoas, aglomeradas em torno das saídas, demorariam mais tempo para abandonar o local. Portanto, as larguras das saídas, calculadas a partir do conceito de filas estabelecido pela NBR 9077 (ABNT, 2001) e IT 11 (CORPO..., 2018a), estariam ainda mais subdimensionadas, aumentando os riscos a que estão submetidos os ocupantes da edificação. Passado 1 min do inicio da evacuação, apenas 271 pessoas (33\%) tinham deixado o local.

No modo Steering é feito um planejamento de trajetória; logo, devido à menor distância para alcançar a saída 1 , há um aumento no quantitativo de pessoas que a utilizam (34\%), ao passo que na simulação 1 foi de $21 \%$. Tal conduta, proposta no 
modo Steering, seria uma aproximação do comportamento real adotado pelas pessoas. $\mathrm{Na}$ Figura 7 é possível observar que a maioria dos ocupantes ainda utiliza a saída 2, porém num percentual menor ao que foi verificado na simulação 1.
Conforme Salyers e Jones (2011), os ocupantes, no modo Steering, modificam seus caminhos e velocidades baseados na distância entre as pessoas e a localização das paredes ao longo de suas vias potenciais. Esse modo leva em conta as colisões entre ocupantes e obstruções, não permitindo que pessoas ocupem o mesmo espaço (como observado na Figura 8) diferenciando-se do modo SFPE.

Figura 8 - Simulação 2 - Número de pessoas (p) evacuadas e tempo de desocupação (s): (a) 819 p e 0 s, (b) 29 p e 15 s, (c) 107 p e 30 s, (d) 423 p e 90 s, (e) 719 p e 150 s (f) 812 p e 180 s

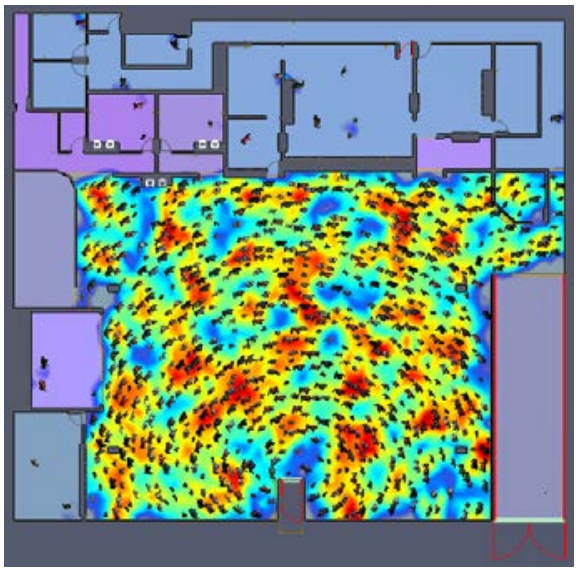

(a)

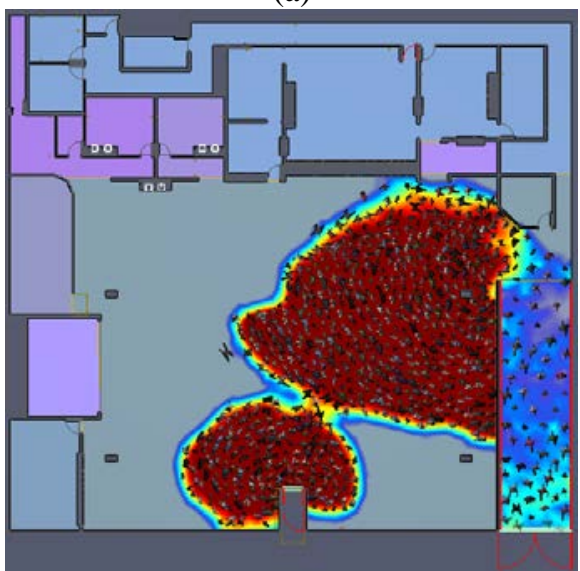

(c)

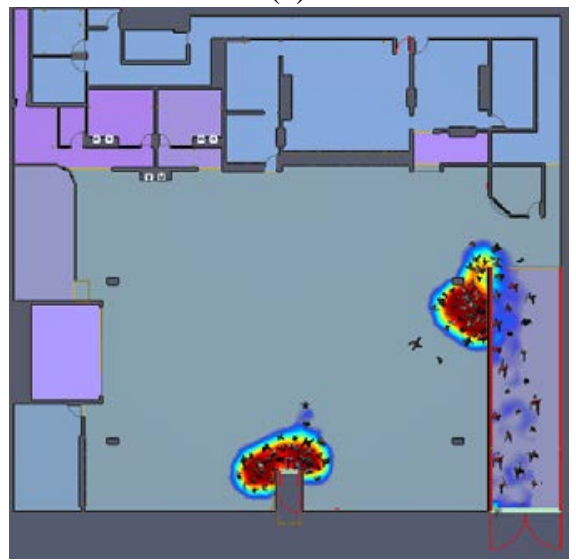

(e)

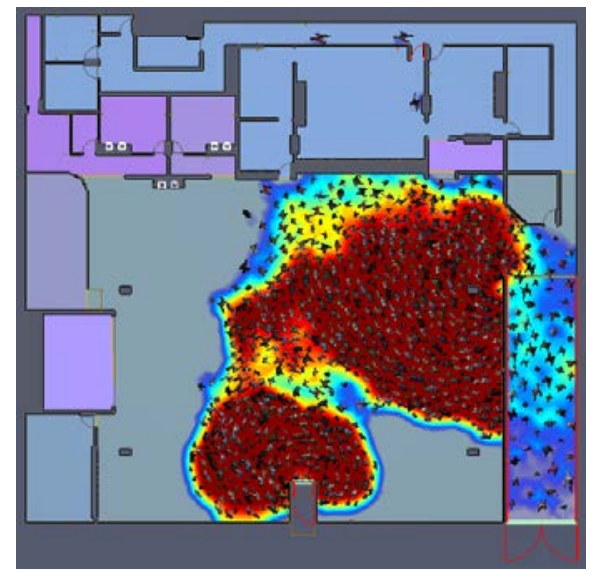

(b)

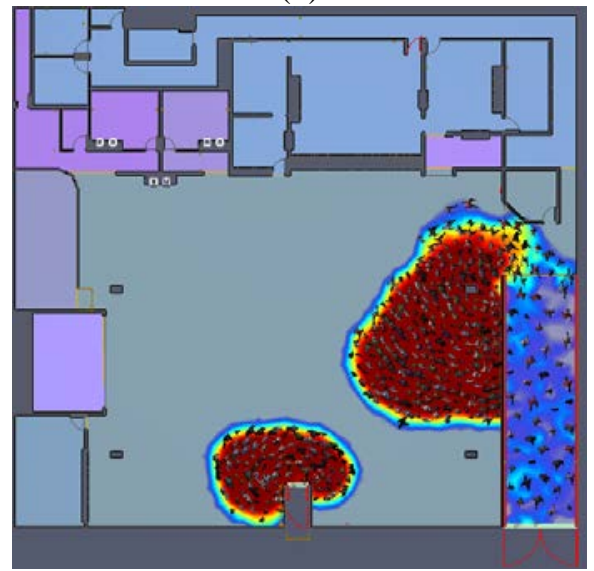

(d)

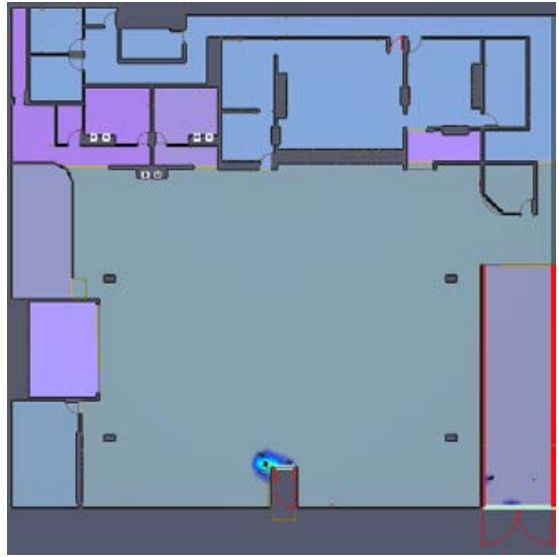

(f)

Densidade Pessoas $/ \mathrm{m}^{2}$

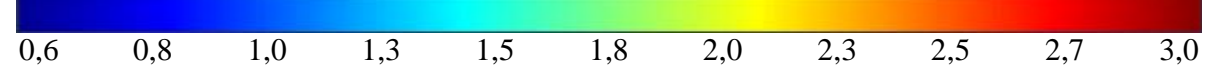


Segundo Helbing, Farkas e Vicsek (2000), durante uma evacuação de emergência os pedestres se aglomeram no espaço em torno do acesso de saída. A velocidade é reduzida decorrente do maior contato corpóreo entre as pessoas, o que causa efeitos adicionais de atrito e aumento na densidade da região. A distribuição das pessoas em volta da passagem lembra a forma geométrica de um arco, como fica visível nas Figuras 8(c) e (d).

O arco é decorrente da tentativa do pedestre desviar obstáculos ou pessoas que estejam muito próximas a ele e se sustenta pela pressão exercida de quem está atrás sobre a pessoa que está na frente, impedindo a saída destes. Eventualmente, quando os arcos se quebram, o fluxo de pedestres que deixam o local aumenta, até que um novo arco se forme novamente.

Essa é outra diferença em relação à simulação 1, na qual só foi possível visualizar filas nas descargas, tendo-se que recorrer à Figura 6 para identificar os gargalos ou congestionamentos das portas. Ainda da observação da Figura 8(c) extrai-se que apenas 107 pessoas abandonaram o local, estando mais de 700 ocupantes aglomerados nesses arcos, situação perigosa, pois segundo Helbing e Mulnár (1995) tempos longos de espera podem gerar ondas de choques devidas à impaciência.

Destaca-se o fato de o maior arco ser formado em torno da rampa da descarga 2. No PSCI a porta de saída 2 e a rampa de acesso possuem $4 \mathrm{~m}$ de largura. Entretanto, no acesso que antecede a rampa, a largura é reduzida para 2,8 m (Figura 9).

Os textos normativos, NBR 9077 (ABNT, 2001) e IT 11 (CORPO..., 2018a), preconizam que as larguras das saídas de emergência devem ser medidas no seu ponto mais estreito. Contudo, no caso estudado, tal estreitamento passa despercebido, pois durante a concepção do PSCI a atenção é voltada para a descarga. Daí a relevância dos modelos computacionais de evacuação que são parte integrante da análise baseada em desempenho para avaliar as condições de fuga da edificação (MATTEDI, 2005), identificando os locais de formação de gargalos ou congestionamentos que não seriam percebidos pela simples análise da planta ou do cálculo manual.

A taxa de fluxo da saída 2 (Tabela 4) é maior tendo em vista sua maior largura e o dobro do valor em relação a taxa de fluxo da saída 1 . Esse fato propicia maior utilização da saída 1 e subutilização da saída 2.

\section{Comparação entre as simulações 1 e 2 e os valores calculados a partir dos dados normativos}

A Tabela 5 apresenta os dados de tempo de evacuação, fluxo específico e taxa de fluxo obtidos nas simulações 1 e 2 e os dados baseados na NBR 9077 (ABNT, 2001) para o estudo de caso. No texto indicado na NBR 9077 (ABNT, 2001) é subentendido que, para locais de reunião de público, as larguras das saídas devem ser calculadas para a evacuação de toda a população existente na edificação em um tempo de 60 s. Baseados nas Equações 1 e 2 propostas pela norma e considerando uma população de 819 pessoas obteve-se, para a edificação uma largura total de saídas 4,95 m, valor inferior à soma das larguras das saídas existentes no projeto que é de 5,20 m.

\section{Figura 9 - Imagem representativa da arquitetura da edificação}

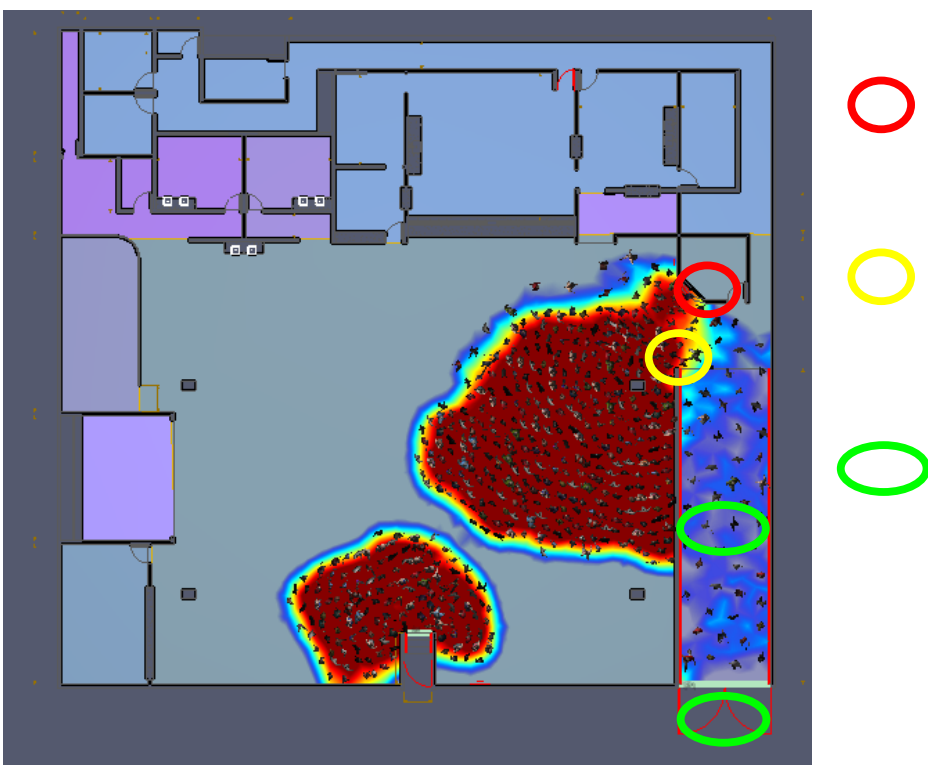

Ambiente que reduz a largura do acesso ao corredor.

Acesso a rampa com largura de 2,80 m.

Rampa e porta da descarga 2 com

largura de 4,00 m. 
Tabela 4 - Taxas de fluxos e fluxos específicos da simulação 2

\begin{tabular}{c|c|c|c|c}
\hline & \multicolumn{2}{|c|}{$\begin{array}{c}\text { Taxa de fluxo } \\
\text { (pessoas/s) }\end{array}$} & \multicolumn{2}{c}{$\begin{array}{c}\text { Fluxo específico } \\
\text { (pessoas/s.m) }\end{array}$} \\
\hline Saída & Médio & Máximo & Médio & Máx \\
\hline $\mathbf{1}$ & 1,53 & 1,74 & 1,28 & 1,45 \\
$\mathbf{2}$ & 3,19 & 4,35 & 0,80 & 1,08 \\
\hline
\end{tabular}

Tabela 5 - Comparação entre valores simulados e normativos

\begin{tabular}{l|c|c|c}
\hline & $\begin{array}{c}\text { Tempo de evacuação } \\
\text { (s) }\end{array}$ & $\begin{array}{c}\text { Fluxo específico } \\
\text { (pessoas/s.m) }\end{array}$ & $\begin{array}{c}\text { Taxa de fluxo } \\
\text { (pessoas/s) }\end{array}$ \\
\hline Simulação 1 & 149 & $1,34^{*}$ & $4,89^{*}$ \\
Simulação 2 & 185 & $1,45^{*}$ & $4,35^{*}$ \\
NBR 9077 (ABNT, 2001) & 60 & 3,03 & 12,12 \\
\hline
\end{tabular}

Nota: *valores máximos obtidos.

Significa que estando a edificação com a lotação máxima permitida, a saída das pessoas deveria ser feita em menos de 1 min; entretanto, as simulações divergem desse valor. Na simulação 1 (modo SFPE) o tempo de evacuação total é $148 \%$ superior ao estabelecido pela norma e na simulação 2 é de $208 \%$.

O valor da taxa de fluxo (Tabela 5) também é superestimado quando calculado com base no fluxo específico adotado pela norma. Nelson e Mowrer (2002) indicam o fluxo específico máximo para corredores, rampas e portas, de 1,3 pessoas/(s.m) para uma densidade de 1,9 pessoa $/ \mathrm{m}^{2}$. Considerando que a densidade para a edificação estudada é de 2 pessoas $/ \mathrm{m}^{2}$, os valores obtidos nas simulações estão bem próximos aos do referido trabalho. Também corroboram com Galea et al. (2004), que estabelecem em seu estudo um fluxo específico de 1,33 pessoas/(s.m) por portas, independentemente de sua dimensão.

Regramentos mais modernos baseados em consolidados estudos de evacuação para estádios de futebol no mundo, a exemplo da IT 12 (CORPO..., 2018b), têm o valor de 1,38 pessoas/(s.m) nas saídas horizontais, valor próximo aos obtidos nas simulações. De fato, tais normas utilizam os conceitos de tempo de saída e de taxa de fluxo para o dimensionamento das saídas de emergência e não mais o conceito de unidade de passagem ainda utilizado pela NBR 9077 (ABNT, 2001) e pela IT 11 (CORPO..., 2018a).

É importante dizer que os valores encontrados nas simulações são influenciados pelo estreitamento do acesso à saída 2, conforme discutido anteriormente. Considerando essa condição e refazendo os cálculos a partir do método indicado na norma, seria obtida uma taxa de fluxo de 8,48 pessoas/s, ainda muito superior aos dados simulados.

\section{Discussão quanto à eficiência normativa do dimensionamento das saídas de emergência em locais de reunião de público}

As primeiras manifestações normativas relevantes no Brasil surgiram na década de 1970 após a ocorrência de grandes incêndios com elevado número de vítimas fatais (BRENTANO, 2015). Segundo Silva (2012), em 1974, logo após um incêndio no Edifício Joelma que matou 179 pessoas, a ABNT publicou a NB 208 - Saídas de Emergência em Edifícios Altos. Em 1978 foi editada a Norma Regulamentadora 23 - Proteção Contra Incêndios, que dispôs regras de proteção contra incêndio na relação empregador/empregado.

Entretanto, tais legislações foram efetivamente implantadas bem mais tarde, após a difusão de tecnologias necessárias para a sua execução. São da década de 1980 as normas sobre alarme e detecção, iluminação de emergência, entre outras, e muito do imediatamente proposto permaneceu inativo, ou quase, por mais algum tempo (GILL; OLIVEIRA; NEGRISOLO, 2008).

Hoje, mais de 40 anos depois, as leis e normas de segurança contra incêndio no país ainda são redigidas com base em experiências observadas a partir de desastres ocorridos. Tais documentos utilizam textos genéricos para abranger todas as edificações, por vezes resultando em exigências que não garantem a segurança almejada e limitam a liberdade do projetista. Um exemplo é o caso da recente Lei Federal n. 13.425 (BRASIL, 2017), popularmente conhecida por "Lei Boate Kiss", que estabelece, em seu artigo $2^{\circ}$ : 
O planejamento urbano a cargo dos Municípios deverá observar normas especiais de prevenção e combate a incêndio e a desastres para locais de grande concentração e circulação de pessoas, editadas pelo poder público municipal, respeitada a legislação estadual pertinente ao tema.

A IT 11 (CORPO..., 2018a) e a NBR 9077 (ABNT, 2001) são exemplos de normas especiais a serem atendidas. Embora tenha sido atualizada em 2018, a IT 11 apresenta a maior parte de seus parâmetros de dimensionamento igual aos da NBR 9077 (ABNT, 2001) que, segundo Ono (2010), já se subsidiava em conceitos mais antigos. Contudo, a norma estadual de São Paulo, em 2014, trouxe algumas exigências novas, motivadas pela tragédia na Boate Kiss, mas sem informar claramente qual o objetivo que se deseja alcançar com as modificações, podendo acarretar na descrença de sua real necessidade e eficácia. Além disso, certas exigências podem inviabilizar o funcionamento de edificações que não as atendam sem se ter a garantia do aumento da segurança.

Todos os dias surgem novos materiais e tecnologias que modificam o ambiente construído e, consequentemente, a segurança de seus ocupantes. As regulamentações de segurança contra incêndio devem acompanhar essa evolução por meio de atualizações periódicas. Nesse contexto, a modelagem matemática é uma importante ferramenta para auxiliar a modificação de normas a partir de parâmetros de desempenho, reduzindo as avaliações meramente prescritivas ainda utilizadas como referencial.

A partir das respostas de tempo de evacuação obtidas nas simulações realizadas foi possível avaliar que, para o caso estudado, tanto a NBR 9077 (ABNT, 2001) quanto a IT 11 (CORPO..., 2018a), consideradas referências de normas de saídas de emergência no Brasil, utilizam como base para o cálculo do dimensionamento dos acessos e portas condições impraticáveis e não deixam claro em seu texto o tempo de evacuação a ser considerado, levando a uma falsa hipótese de que a evacuação poderá ocorrer em 1 min. Alves, Campos e Braga (2008) e Ono e Vitorino (2010) também corroboram com a opinião que não há definição explicita, na NBR 9077 (ABNT, 2001), do tempo de evacuação estabelecido na definição da capacidade de unidade de passagem.

Outra questão observada é a dinâmica de movimento. Nessa pesquisa o menor tempo de evacuação foi obtido a partir da dinâmica do SFPE, que estabelece a saída em fila (também utilizada como base pela NBR 9077 (ABNT, 2001) e pela IT
11 (CORPO..., 2018a)) o que, na prática, dificilmente se observa. Quando realizada a simulação usando o modo Steering, mais semelhante ao movimento real realizado pelas pessoas, o tempo de evacuação aumenta em aproximadamente 24\%. Vale ressaltar que as simulações foram feitas sem considerar os tempos de pré-evacuação que majorariam ainda mais o tempo total de saída. Alves, Campos e Braga (2008), estudando edificações comerciais, também obtiveram tempos de evacuação bem superiores aos indicados pela NBR 9077 (ABNT, 2001).

Diante do exposto, observa-se que o cálculo de dimensionamento de acessos e portas de locais de reunião de público proposto nas normas de saídas de emergência vigentes no país e utilizado como base nos projetos arquitetônicos pode não atender às condições mínimas de segurança que são necessárias para garantir a integridade das pessoas durante um evento de evacuação.

\section{Conclusão}

Os modelos matemáticos de dinâmica de evacuação são importantes ferramentas de auxílio à elaboração de projetos de segurança contra incêndio, pois permitem avaliar aspectos variados, dando embasamento para a construção de edificações mais seguras. Tais modelos também são úteis na verificação das diretrizes indicadas pelas normas técnicas que são instrumentos balizadores de projetos.

A partir dos resultados de tempo de evacuação, dinâmica de movimento e taxa de fluxo avaliados, pôde-se constatar que as premissas estabelecidas pelos textos normativos não foram alcançadas para este estudo. O menor tempo de evacuação (149 s), obtido nas simulações utilizando a dinâmica do SFPE (simulação 1), foi bem superior ao preconizado pela NBR 9077 (ABNT, 2001) e pela IT 11 (CORPO..., 2018a), que subentendem ocorrer em 60 s. Quando realizada a simulação usando o modo Steering (simulação 2) o tempo de evacuação aumenta para $185 \mathrm{~s}$ (mais de $3 \mathrm{~min}$ ). Quanto ao fluxo específico, o maior valor obtido foi de 1,45 pessoas/s.m, ainda inferior ao que pode ser extraído das normas de saídas de emergência nacionais e estaduais que, supostamente, seria de 3,03 pessoas/s.m.

Conclui-se que as divergências obtidas entre a modelagem computacional e os valores normativos ocorrem provavelmente porque esses últimos utilizam o conceito de unidade de passagem em detrimento aos conceitos de tempo de evacuação e taxa de fluxo. Vale salientar que as conclusões aqui obtidas são pautadas em um estudo de caso; sendo assim, não são definitivas e nem podem ser 
generalizadas. Na análise da adequação de saídas de emergência, além do dimensionamento, outros fatores podem interferir nos resultados, tais como o perfil e o comportamento dos ocupantes, as condições de acesso às saídas, a existência de sinalização adequada, a distância máxima percorrida e os tempos de alarme, detecção e préevacuação.

Por outro lado, apesar dos resultados obtidos neste trabalho não serem suficientes para avaliar definitivamente a adequação das saídas de emergência em locais de reunião de público, reforça-se a importância da revisão das normas existentes ou a elaboração de novas que levem em consideração parâmetros de desempenho de forma a representar melhor a realidade e garantir a segurança das pessoas em clubes sociais.

\section{Referências}

ALMEIDA, J. E. S. C. Modelação e Simulação do Comportamento Humano na Evacuação de Edifícios. In: NFPA-APSEI. FIRE \& SECURITY, Estoril, 2012. Anais... Estoril, 2012.

ALVES, A. B. C. G.; CAMPOS, A. T.; BRAGA, G. C. B. Simulação Computacional de Incêndio Aplicada ao Projeto de Arquitetura. São Paulo, 2008. Disponível em:

<https://www.usp.br/nutau/CD/71\%20196.pdf>. Acesso em: 26 maio 2018.

AMOR, H. B.; MURRAY, J.; OBST, O. Fast, Neat and Under Control: inverse steering behaviors for physical autonomous agents. In: RABIN, S. Ai Game Programming Wisdom 3. Charles River Media Publisher, 2006.

ASSOCIAÇÃO BRASILEIRA DE NORMAS TÉCNICAS. NBR 9077: saídas de emergência em edifícios. Rio de Janeiro, 2001.

ASSOCIAÇÃO BRASILEIRA DE NORMAS TÉCNICAS. Instrução Administrativa (IA) 07.20.02: elaboração de norma brasileira. Rio de Janeiro, 2014.

BASTOS, S. F.; SABRÁ, F. G.; ROSA, R.: SizeBR: o estudo antropométrico brasileiro. In: INTERNATIONAL CONFERENCE AND EXHIBITIONON 3D BODY SCANNING TECHNOLOGIES, 4., Long Beach, 2013. Proceedings... Long Beach, 2013.

BRASIL. Lei $\mathrm{n}^{\circ}$ 13.425, de 30 de março de 2017. Prevenção e combate a incêndios e desastres. Brasília, DF, 2017. Diário Oficial da União, DF, 31 de março de 2017.
BRENTANO, T. A Proteção Contra Incêndio no Projeto de Edificações. 3. ed. Porto Alegre: Edição do autor, 2015.

CLARET, A. M.; MATTEDI, D. L. Estudo da Prescritividade das Normas Técnicas Brasileiras de Segurança Contra Incêndio. REM. Revista Escola de Minas, v. 64, n. 3, p. 265-271, jul./set. 2011.

\section{CORPO DE BOMBEIROS MILITAR DA}

PARAÍBA. Acervo Interno. Centro de Atividades

Técnicas. Paraíba, 2016.

CORPO DE BOMBEIROS POLÍCIA MILITAR DE SÃO PAULO. Instrução Técnica n. 11: saídas de emergência. São Paulo, 2018a.

CORPO DE BOMBEIROS POLÍCIA MILITAR DE SÃO PAULO. Instrução Técnica n. 12: dimensionamento de Lotação e Saídas de Emergência em Centros Esportivos e de Exibição. São Paulo, 2018b.

DINENNO, P. J. et al. The SFPE Handbook of Fire Protection Engineering. ${ }^{\text {rd }}$. ed. Quincy: National Fire Protection Association, 2002.

GALEA, E. R. et al. BuildingExodus V. 4.0: user guide and technical manual. London: University of Greenwich, 2004.

GILL, A. A.; OLIVEIRA, S. A. de; NEGRISOLO, W. Aprendendo Com os Grandes Incêndio. In: SEITO, A. I. et al. (Orgs.). A Segurança Contra Incendio no Brasil. São Paulo: Projeto Editora, 2008.

GOUVEIA, A. M. C.; ETRUSCO, P. Tempo de Escape em Edificações: os desafios do modelamento de incêndio no Brasil. Revista Escola de Minas, v. 55, n. 4, p. 257-261, out./dez. 2002.

HELBING, D.; FARKAS, I.; VICSEK, T. Simulating Dynamical Features of Escape Panic. Revista Nature, London, v. 407, p. 487-490, set. 2000.

HELBING, D.; MULNÁR, P. Social Force Model For Pedestrian Dynamics. Physical Review E, v. 5, n. 5, p. 4282-4286, may 1995.

KULIGOWSKI, E. D.; PEACOCK, R. D.; HOSKINS, B. L. Technical Note 1680: a review of building evacuation models. $2^{\text {nd }}$. ed. National Institute of Standards and Technology, 2010.

LANTZ, C. E. Modelling Ascending Stair Evacuation. Lund, 2015. $84 \mathrm{f}$. Thesis - Master (International Master of Science in Fire Safety Engineering), Lund University, Lund, 2015. 
MATTEDI, D. L. Uma Contribuição ao Estudo do Processo de Projeto de Segurança Contra Incêndio Baseado em Desempenho. Ouro Preto, 2005. 227 f. Dissertação (Mestrado em Engenharia Civil) - Escola de Minas, Universidade Federal de Ouro Preto, Ouro Preto, 2005.

MONTEneGro, M. L. O. Análise de Desempenho das Saídas de Emergência por Meio de Simulações Computacionais: o caso de projetos de edifícios universitários. Natal, 2016. 179f. Dissertação (Mestrado em Arquitetura e Urbanismo) - Escola de Arquitetura e Urbanismo, Universidade Federal do Rio Grande do Norte, Natal, 2016.

MUNIZ, R. M. D. O Uso de Simuladores Como Uma Ferramenta de Auxílio na Definição dos Requisitos De planos de Retirada de Emergência: estudo de caso em um centro de pesquisas de uma instituição pública de ensino superior. Rio de Janeiro, 2013. 239 f. Dissertação (Mestrado em Engenharia Ambiental) - Escola de Engenharia, Universidade Federal do Rio de Janeiro, Rio de Janeiro, 2013.

NELSON, H. E.; MOWRER, F. W. Emergency Movement. In: SFPE Handbook of Fire Protection Engineering. $3^{\text {th. }}$ ed. Maryland: National Fire Protection Association, 2002.

NI, B.; LI, Z.; LI, X. Agent-Based Evacuation in Passenger Ships Using a Goal-Driven DecisionMaking Model. Polish Maritime Research, v. 24; n. 2, n. 94, p. 56-67, 2017.

ONO, R. O Impacto do Método de Dimensionamento das Saídas de Emergência Sobre o Projeto Arquitetônico de Edifícios Altos: uma análise crítica e proposta de aprimoramento. São Paulo, 2010. 223 f. Tese (Doutorado em Tecnologia da Arquitetura) Faculdade de Arquitetura e Urbanismo, Universidade de São Paulo, São Paulo, 2010.

ONO, R. Parâmetros para Garantia da Qualidade do Projeto de Segurança Contra Incêndio em Edifícios Altos. Ambiente Construído, Porto Alegre, v. 7, n. 1, p. 97-113, jan./mar. 2007.

ONO, R.; VITORINO, F. Desempenho da Largura das Portas no Tempo de Abandono de Compartimentos. In: ENCONTRO NACIONAL DE TECNOLOGIA DE AMBIENTE CONSTRUÍDO, 13., Canela, 2010. Anais... Canela: UFRS, ENTAC, 2010.

REYNOLD, C. W. Steering Behaviors For Autonomous Characters. In: PROCEEDINGS of the Game Developers Conference, 1999. Miller Freeman Game Group, San Francisco, 1999.
RONCHI, E. et al. Human Behaviour in Road Tunnel Fires: comparison between egress models (FDS+Evac, STEPS, Pathfinder). In: INTERNATIONAL CONFERENCE ON FIRE SCIENCE AND ENGINEERING INTERFLAM, 2010. Proceedings... United Hingdon, 2010.

SALYERS, B.; JONES, B. Evacuation Modeling Dependence Input Parameters. In: PROCEEDINGS, FIRE AND EVACUATION MODELING TECHNICAL CONFERENCE, Maryland, 2011. Proceedings... Maryland, 2011.

SENA, L. F. de; ONO, R. Avaliação do Dimensionamento de Saídas de Emergência e Tempo de Abandono de Edificações Utilizando Método de Simulação Computacional. São Paulo, 2010. Disponível em:

$<$ https://www.usp.br/nutau/sem_nutau_2010/meto dologias /ono_rosaria.pdf>. Acesso em: 25 maio 2018.

SILVA, V. P. Projeto de Estruturas de Concreto em Situação de Incêndio: conforme ABNT NBR 15200:2012. São Paulo: Editora Blucher, 2012.

SOCIETY OF FIRE PROTECTION ENGINEERS. Engineering Guide: human behavior in fire. $2^{\text {nd }}$. ed. 2017.

SOUZA, W. P. de. Reação ao Fogo dos Materiais: uma avaliação dos métodos de projeto de saídas de emergência em edificações não industriais. Ouro Preto, 2007. 120 f. Dissertação (Mestrado em Engenharia de Materiais) - Escola de Engenharia, Universidade Federal de Ouro Preto, Ouro Preto, 2007.

SZILAGYI, C. The Comparison of the Results of a Full Scale Evacuation Test to the Calculation Method of Hungarian Regulations and to the Pathfinder Software. In: APPLICATION OF STRUCTURAL FIRE ENGINEERING, Czech Republic, 2013. Proceedings... Czech Republic, 2013.

TAVARES, R. M. Prescriptive Codes vs Performance-Based Codes: which one is the best fire safety code for the Brazilian context. Safety Science Monitor, v. 12, n. 1, p. 1-10, 2008.

THUNDERHEAD ENGINEERING. Pathfinder Resources: verification and validation. Disponível em:

$<$ https://www.thunderheadeng.com/pathfinder/reso urces/>. Acesso em: 15 maio 2018.

VALENTIN, M. V. Saídas de Emergência em Edifícios Escolares. São Paulo, 2008. 362 f. Dissertação (Mestrado em Arquitetura e Urbanismo) - Faculdade de Arquitetura e Urbanismo, Universidade de São Paulo, São Paulo, 2008. 
ZHANG, J.; SEYFRIED, A. Empirical Characteristics of Different Types of Pedestrian Streams. Procedia Engineering, v. 62, p. 655662, 2013.

\section{Diego de Souza Martins}

30 Batalhão de Bombeiros Militar | Corpo de Bombeiros Militar da Paraíba | Rua Almeida Barreto, 246, Centro | Guarabira - PB - Brasil | CEP 58200-000 | Tel.: (83) 3271-2460 | E-mail: ddiegomartins@hotmail.com

\section{Andréa Carla Lima Rodrigues}

Unidade Acadêmica de Engenharia Civil | Universidade Federal de Campina Grande | Rua Aprígio Veloso, 882, Bodocongó | Campina Grande - PB - Brasil | CEP 58100-970 | Tel.: (83) 2101-1284 | E-mail: andreaufcg@gmail.com

\section{George Cajaty Barbosa Braga}

Diretoria de Serviços Técnicos | Corpo de Bombeiros Militar do Distrito Federal | Setor Policial Sul, Área Especial 3, Asa Sul | Brasília - DF - Brasil | CEP 70620-000 | Tel.: (61) 3901-3602 | E-mail: george.braga@gmail.com

\section{Revista Ambiente Construído}

Associação Nacional de Tecnologia do Ambiente Construído

Av. Osvaldo Aranha, 99 - 3o andar, Centro

Porto Alegre - RS - Brasil

CEP $90035-190$

Telefone: +55 (51) 3308-4084

Fax: +55 (51) 3308-4054

www. seer. ufrgs. br/ ambienteconstruido

E-mail: ambienteconstruido@ufrgs.br

(c) (1) This is an open-access article distributed under the terms of the Creative Commons Attribution License. 